\title{
Childhood Diarrhea and its management- a community based study estimating knowledge, attitude and practice of Saudi Mothers, Saudi Arabia
}

\author{
SULTHAN GHADEER ${ }^{1}$, syeed A ${ }^{1}$, Abdulaziz Alhossan ${ }^{2}$, salmeen babelghaith ${ }^{1}$, ziyadh Al \\ Rabiah ${ }^{1}$, and Mohammed N. Al-Arifi ${ }^{1}$ \\ ${ }^{1}$ King Saud University \\ ${ }^{2}$ King Saud University College of Pharmacy
}

January 9, 2021

\begin{abstract}
Aim To demonstrate the best home care of children with diarrhea in our community by investigating certain knowledge deficiencies, specific inappropriate attitudes, and particular improper practice toward children diarrhea and its management, this study was conducted to evaluate knowledge, attitude and practice of Saudi mothers towards diarrhea in their children and its management at home. Methods Online cross-sectional validated online survey targeting Saudi mothers who are living in Saudi Arabia was used to collect data from the beginning of March to the end of April 2019. Results A total of 1140 mothers (52.1\% of them are housewives) participated in the study. About of $40.3 \%$ of participating mothers believed that childhood diarrhea is major problem in Saudi community; however, Almost $23 \%$ of the participants were unable to identify any critical sign of sever diarrhea, and around $66 \%$ falsely stated that diarrhea is caused by teething. Although of $62 \%$ of our participating mothers knew about the oral rehydration therapy (ORS), only $23.5 \%$ of them used it for their children. Conclusion Adequate knowledge of mothers about the critical sings, causes, transmission, prevention, and management of childhood diarrhea should be applied in simple language to communicate the health-related information in clear manner.
\end{abstract}

Childhood Diarrhea and its management- a community based study estimating knowledge, attitude and practice of Saudi Mothers, Saudi Arabia

Aim

To demonstrate the best home care of children with diarrhea in our community by investigating certain knowledge deficiencies, specific inappropriate attitudes, and particular improper practice toward children diarrhea and its management, this study was conducted to evaluate knowledge, attitude and practice of Saudi mothers towards diarrhea in their children and its management at home.

\section{Methods}

Online cross-sectional validated online survey targeting Saudi mothers who are living in Saudi Arabia was used to collect data from the beginning of March to the end of April 2019.

\section{Results}

A total of 1140 mothers (52.1\% of them are housewives) participated in the study. About of $40.3 \%$ of participating mothers believed that childhood diarrhea is major problem in Saudi community; however, Almost $23 \%$ of the participants were unable to identify any critical sign of sever diarrhea, and around $66 \%$ falsely stated that diarrhea is caused by teething. Although of $62 \%$ of our participating mothers knew about the oral rehydration therapy (ORS), only $23.5 \%$ of them used it for their children. 


\section{Conclusion}

Adequate knowledge of mothers about the critical sings, causes, transmission, prevention, and management of childhood diarrhea should be applied in simple language to communicate the health-related information in clear manner.

Key words: Diarrhea; Saudi Arabia; Knowledge; Attitude; Children; Mother

\section{What's known}

- Every parents working hard to keep their children's healthy at all stages of child, and parent's knowledge and attitudes about health is very important

- Diarrhea is a common illness that is considered a major threat to children, and it may lead to death in developing countries particularly amongst children aged up to 5 years

- Enhancing mothers' proper knowledge and demonstrating appropriate practice is a key to prevent or halt the progression of diarrhea. However, mothers' harmful practices such as nourishment limitation, breast feeding avoidance, and utilization of inappropriate conventional therapy or wrong prescription have been reported.

\section{What's new}

In most cases, diarrhea can be treated at home by oral rehydration therapy (ORT) that has significantly decreased the mortality related to diarrhea disease.13 Although this method of treatment is cheap, adequate, reasonable, and safe, few mothers listed that the aim of using (ORS) during diarrhea is to treat dehydration of diarrhea.

In order to demonstrate the best home care of children with diarrhea in our community(Saudi) by investigating certain knowledge deficiencies, specific inappropriate attitude, and particular improper practice toward children diarrhea and its management

\section{INTRODUCTION}

Diarrhea is a common illness that is considered a major threat to children, and it may lead to death in developing countries particularly amongst children aged up to 5 years ${ }^{1-3}$ Twelve million children are estimated to die in developing countries before the age of five years. Around $70 \%$ of those children die because of five medical issues; one of them is diarrhea. ${ }^{1,4}$ Despite of that age, climate changes, and the use of rotavirus vaccine can contribute to variations in pathogen-causative diarrhea, rotavirus was the most common causative pathogen especially in unvaccinated children against rotavirus. ${ }^{5}$ In Saudi Arabia, rotavirus was noticed in $41.3 \%$ to $65.5 \%$ of cases causing children diarrhea ${ }^{6,7}$ In addition to microbial-induced diarrhea, Diarrhea can result from intolerance of certain kinds of food particularly lactose containing milk. ${ }^{8}$

Regardless of diarrhea-induced causes, dirty weaning food, improper nourishing practice, absence of clean water, poor hand washing, constrained sterile transfer of waste, poor lodging conditions, and absence of access to satisfactory and moderate social insurance are aggravating factors of diarrhea in children under 5 years old. ${ }^{9}$ A study in Saudi Arabia reported that environmental risk factors associated children diarrhea included sewage leakage near the home, eating out after school hours and utilizing reusable cloths or sponges to dry dishes. ${ }^{10}$

Enhancing mothers' proper knowledge and demonstrating appropriate practice is a key to prevent or halt the progression of diarrhea. However, mothers' harmful practices such as nourishment limitation, breast feeding avoidance, and utilization of inappropriate conventional therapy or wrong prescription have been reported. ${ }^{11}$ In addition, the knowledge of mothers toward the signs of dehydration secondary to diarrhea is poor. ${ }^{2,12}$ In most cases, diarrhea can be treated at home by oral rehydration therapy (ORT) that has significantly decreased the mortality related to diarrhea disease. ${ }^{13}$ Although this method of treatment is cheap, adequate, reasonable, and safe, few mothers listed that the aim of using (ORS) during diarrhea is to treat dehydration of diarrhea. ${ }^{2,13}$ In order to demonstrate the best home care of children with diarrhea in our community by 
investigating certain knowledge deficiencies, specific inappropriate attitude, and particular improper practice toward children diarrhea and its management, the aim of this study is to evaluate knowledge, attitude and practice of mothers towards diarrhea in children and its management at home.

\section{METHODS AND MATERIALS}

Online cross-sectional survey based study targeting mothers who are living in Saudi Arabia were carried out to measure knowledge, attitude and practice of mothers towards diarrhea and its management in their children at home. The data collection was carried out from the beginning of March to the end of April 2019. The questionnaires for this study was prepared after an extensive literature review from similar studies published in this regard ${ }^{2,13}$. The questionnaires for this study grouped in four parts. The first part was to collect demographic data (such as age of mother, mother's education level, mother's job, child's age, etc.). The second part is the knowledge domain questions with the multiple-choice options discussing subjects like signs and symptoms of diarrhea, diarrhea causes, preventive measures and critical signs of diarrhea as well as critical signs of dehydration. The third part focused on manner of management practice of diarrhea at home. The fourth part was the attitude domain questions that were composed of 11 questions assessed by 5 point Likert Scale (strongly agree, agree, neutral, disagree, and strongly disagree). A panel of 3 members (two professors and a researcher) from college of pharmacy, king Saud university who were experts in preparing the study tool were reviewed the questionnaire. The survey was translated into Arabic language by an independent translator, and reviewed again for the appropriateness of language before testing its validity. The questionnaire was then validated through randomly selected 10 respondents in a pilot study carried out at college of pharmacy king Saud university. The respondents recruited in the pilot study were mothers and did not include in the final results or had no contact with the subjects of the study. Reliability test was determined using Cronbach's alpha of the questionnaire and it was found 0.73 .

The sample size for this study was calculated using an online sample size calculator (http://www.raosoft.com/samplesize.html) by assuming a larger population size with a margin of error $\pm 5 \%$ and a confidence level of $95 \%$, which resulted in a sample of 384 individuals. ${ }^{14}$ Statistical Package for Social Sciences version 25 (SPSS) software was applied to analyze the data. Descriptive statistics and Chi-squared test were also used.

\section{RESULTS}

A total of 1140 respondents filled the questionnaire. About $24 \%$ of respondents were aged from 36 to 40 years, and only $5.4 \%$ of respondents received no formal education. More than half of mothers were housewife (52.1\%). Slight more than one third of children were aged above 2 years. The demographic of mothers and their children are summarized in Table 1. Table 1. Demographic data of mothers and their children

\begin{tabular}{ll}
\hline Variables & Number \\
\hline Age of the Mothers (years) 18-20 21-25 26-30 31-35 36-40 more than 41 years & 1301301661922712 \\
Education level Illiterate Primary school/ secondary school High school University Postgraduate & 62160244479195 \\
Job Employer Health staff Housewife Students Other's & 427685943912 \\
Insurance None Governmental Private & 329482329 \\
Age of the child (years) Less than on year 1-2 years Above 2 years & 217226697 \\
Gender of a child [?] Male Female & 456675 \\
\hline
\end{tabular}

\section{*Missing Data}

In this study, mother rated the critical signs of childhood diarrhea as follows: blood in the stool (49\%), followed by thirst and dry mouth (32.1\%), and loss of stretchiness of the skin (24.3\%). Nearly half (49.9\%) of mothers believed that diarrhea is caused by eating dirty food. Table 2 shows mothers' knowledge about childhood diarrhea.

Table 2. Mothers' knowledge and practice about diarrhea and its managements 
Variables

Critical signs and symptoms of diarrhea* Passage of $>3$ loose stools with blood in 24 hours Thirst and dry mouth Te Cause/mode of transmission of diarrhea* Drinking bad/dirty water Eating dirty food Eating with dirty hands Eating Management of child's diarrhea Visit the physician Visit the pharmacist Use ORS Give homemade fluids Feed the chil

*Multiple-answers question

In this study, the most reported practice among mothers towards management of their child's diarrhea included seeing the physicians (68.9\%), giving homemade fluids (52.6\%), using ORS (23.0) and visiting pharmacists (20.4) (Table 2).

In this study, about $62 \%$ of mothers know the ORS, but only $53.5 \%$ of them recognized that ORS could prevent child from getting dehydrated. The resources of information for utilizing ORS in childhood diarrhea were gained mainly from medical prescription (50.3\%), followed by family $(15.7 \%)$ and then by consultation of pharmacists $(15.1 \%)$ as presented in Table 3.

Table 3. Mothers' knowledge about the use of ORS

\begin{tabular}{lll}
\hline Characteristic & Number & Percentage \\
\hline $\begin{array}{l}\text { Do you know the ORS? Yes } \\
\text { No }\end{array}$ & 706434 & 61.938 .1 \\
$\begin{array}{l}\text { Role of ORS solution in diarrhea Prevents child from getting dehydrated } \\
\text { Either increases or decreases diarrhea }\end{array}$ & 61018377 & 53.516 .16 .8 \\
$\begin{array}{l}\text { No role in diarrhea treatment } \\
\text { Sources information of use ORS Medical prescription }\end{array}$ & 5731721791123150.315 .115 .79 .82 .7 \\
$\begin{array}{l}\text { Consultation of pharmacists } \\
\text { Family } \\
\text { Internet }\end{array}$ & & \\
TV & & \\
\hline
\end{tabular}

In this study, around $33.5 \%$ of mothers thought diarrhea can attack bottle-feed children. Majority of mothers $(65.9 \%)$ reported that teething is the main cause of diarrhea. The disagreement of that "liquid food aggravates diarrhea" were reported by $22.5 \%$ of the mothers. About $41 \%$ mothers thought that diarrhea is a problem in the Saudi community, and $60.9 \%$ of mothers stated that handwashing prevents diarrhea. More details on mothers' attitude on childhood diarrhea is showed in Table 4.

Table 4. Mothers' attitude about childhood diarrhea

\begin{tabular}{llllll}
\hline Questionnaires & $\begin{array}{l}\text { Strongly agree n } \\
(\%)\end{array}$ & Agree n $(\%)$ & Neutral n (\%) & Disagree n (\%) & $\begin{array}{l}\text { Strongly } \\
\text { disagree n }(\%)\end{array}$ \\
\hline $\begin{array}{l}\text { Diarrhea } \\
\text { attacks mostly } \\
\text { bottle-feed } \\
\text { children }\end{array}$ & $146(12.8)$ & $236(20.7)$ & $522(45.8)$ & $180(15.8)$ & $56(4.9)$ \\
$\begin{array}{l}\text { Diarrhea is a } \\
\text { disease of the } \\
\text { poor }\end{array}$ & $36(3.2)$ & $49(4.3)$ & $223(19.6)$ & $431(37.8)$ & $401(35.2)$ \\
$\begin{array}{l}\text { Diarrhea is a } \\
\text { problem in the } \\
\text { community }\end{array}$ & $124(10.9)$ & $347(30.4)$ & $411(36.1)$ & $190(16.7)$ & $68(6.0)$
\end{tabular}




\begin{tabular}{llllll}
\hline Questionnaires & $\begin{array}{l}\text { Strongly agree n } \\
(\%)\end{array}$ & Agree n (\%) & Neutral n (\%) & Disagree n (\%) & $\begin{array}{l}\text { Strongly } \\
\text { disagree n }(\%)\end{array}$ \\
\hline $\begin{array}{l}\text { Teething } \\
\text { causes } \\
\text { diarrhea }\end{array}$ & $282(24.7)$ & $470(41.2)$ & $239(21.0)$ & $105(9.2)$ & $44(3.9)$ \\
$\begin{array}{l}\text { Diarrhea is a } \\
\text { curable disease }\end{array}$ & $559(49.0)$ & $449(39.4)$ & $81(7.1)$ & $30(2.6)$ & $21(1.8)$ \\
$\begin{array}{l}\text { Liquid food } \\
\text { aggravates }\end{array}$ & $111(9.7)$ & $243(21.3)$ & $529(46.4)$ & $209(18.3)$ & $48(4.2)$ \\
diarrhea & & & & \\
$\begin{array}{l}\text { Oral } \\
\text { rehydration }\end{array}$ & $141(12.4)$ & $368(32.3)$ & $485(42.5)$ & $122(10.7)$ & $24(2.1)$ \\
$\begin{array}{l}\text { salts solution } \\
\text { cures diarrhea }\end{array}$ & $120(10.5)$ & $196(17.2)$ & $648(56.8)$ & $133(11.7)$ & $43(3.8)$ \\
$\begin{array}{l}\text { Human feces } \\
\text { are a source of } \\
\text { diarrhea }\end{array}$ & & & & \\
$\begin{array}{l}\text { Handwashing } \\
\text { prevents } \\
\text { diarrhea }\end{array}$ & $248(21.8)$ & $446(39.1)$ & $264(23.2)$ & $122(10.7)$ & $60(5.3)$ \\
\hline
\end{tabular}

\section{Discussion}

This study assessed the knowledge of mothers about the critical signs of diarrhea. About $49 \%$ of the mothers stated that the passage of three or more loose stools with blood during the day is an obvious critical sign of diarrhea that require hospital or physician visit, and almost $23 \%$ reported no knowledge of any critical sign of diarrhea. These results showed low knowledge among Saudi mothers about the critical sings of diarrhea, but their knowledge of the critical signs of diarrhea were higher compared to other mothers in different communities. A study carried out in Ethiopia found that $39.5 \%$ of mothers stated that passage of three or more loose stools with blood during the day is mark of severe diarrhea. ${ }^{15} \mathrm{~A}$ similar study was done in rural setting of Kenya determined that majority of mothers $(76.4 \%)$ did not identify the critical signs of childhood diarrhea. ${ }^{16}$ A study from Nepal reported that $20.8 \%$ of mothers identified the red-colored diarrhea as "the most dangerous diarrhea". ${ }^{2}$ The critical signs of dehydration have the similar importance of bloody diarrhea, and the participating mothers in our study were unable to identify the most common signs of dehydration. Only $32.1 \%, 11.6 \%$, and $24.3 \%$ were able to recognize thirst/dry mouth, tearless eyes, and loss of strictness of skin respectively as the critical signs of dehydration secondary to diarrhea. The poor knowledge and unrecognized sings of dehydration among mothers are noticed globally. ${ }^{2,17-19}$ Adequate knowledge of mothers about the critical sings of childhood diarrhea is essential as the early referral of child with severe diarrhea is fundamental for appropriate treatment. ${ }^{15}$

Poor sanitation of food and water may lead to diarrhea with approximately 3000 deaths and 135,000 hospitalizations annually secondary to food-borne transmission of diarrhea causative pathogens in the United States. ${ }^{20}$ With the regards for the causes and transmission of diarrhea, nearly $50 \%$ of participating mothers believed that eating polluted food is the most common cause of childhood diarrhea, and only $31 \%$ of mothers identified drinking unclean water as the reason for childhood diarrhea. In consistent with our findings, many studies reported low level of mothers towards causes and transmission of diarrhea. ${ }^{2,16,22}$ A study from Nigeria reported that the most common causes for childhood diarrhea were contaminated food (24.1\%) and unclean water (11.3\%). ${ }^{8}$ Another study from Iran showed that only $24.66 \%$ of mothers knew that the unclean water can cause diarrhea. ${ }^{22}$ A study was carried out in Malawi reported that $55 \%$ of mothers stated that unhealthy water is the main causes of diarrhea. ${ }^{23}$ The change in knowledge of childhood diarrhea could be due to variance in mothers' education levels. 
The misconception between teething and diarrhea seems disseminated widely. The results of present study showed that $66 \%$ of mothers stated teething is a reason of their children diarrhea. These results come agreed with other studies from different countries. ${ }^{8,22}$ In addition to the wrong belief of association between diarrhea and teething, mothers tend to consider diarrhea secondary to teething as "non-serious diarrhea", and they may deal with it loosely even if it's accompanied by critical signs like dehydration. ${ }^{24}$ The efforts should be applied to educate the mothers about the critical signs of children diarrhea and to disassociate the belief link between diarrhea and teething.

The mothers' sufficient knowledge on reasons, prevention and management of diarrhea utilizing proper therapies is the key for home management of childhood diarrhea. ${ }^{14,25}$ According to the Integrated Management of Childhood Illness (IMCI) guidelines, the use of ORS is the principle therapy of diarrhea ${ }^{26}$. However, the use of ORS seemed not highly encouraging among mothers. Although of $62 \%$ of our participating mothers knew about the ORS, only $23.5 \%$ of them used it for their children. Similar findings were reported. A study from Nigeria reported that most of mothers (63\%) were aware of ORS, but $27 \%$ of them used it for their children.8 In another study did in Pakistan mentioned that 58\% mothers used ORS to treat their childhood diarrhea disease. ${ }^{12}$ Also in our study, it was found the main resources of mothers regarding ORS usage were medical prescriptions (50.3\%), family/relatives/friends (15.7\%), and pharmacists (15.1\%). In a similar study the two main resources of ORS information were families/friends (76\%) and pediatricians (58\%). ${ }^{27}$ Despite of $53.3 \%$ of our participants reports that "ORS prevents a child from getting dehydrated", few mothers are using ORS (23.5\%). The reason for a few mothers used ORS could be due to their level of education and awareness of the mothers on diarrhea management due to inadequate public information on this issue.

Due to the high rate of literacy and social media usage among Saudis, ${ }^{28,29}$ and the aim of study to assess the knowledge, attitude, and practice of mothers towards childhood diarrhea from community perspective, the study was conducted online to diminish geographical dependence. The study was performed with significance that mothers' knowledge of childhood diarrhea prevention and management would decrease the unnecessary hospital or clinic visits; however, most of the participating mothers $(68.9 \%)$ seek treatment from medical doctor for their children with diarrhea. This practice of mother was observed in previous study. ${ }^{15}$ In contrast, our subjects showed good preventive measure. The majority of mothers $(70.9 \%)$ believed that handwashing, which is one essential measure to decrease the prevalence of diarrhea, ${ }^{30}$ prevents childhood diarrhea.

\section{CONCLUSION}

About of $40.3 \%$ of participating mothers believed that childhood diarrhea is major problem in Saudi community. These beliefs are supported by reports mentioned the prevalence of diarrhea is high in some area of Saudi Arabia. ${ }^{1}$ However, insufficient knowledge of childhood diarrhea and its management were observed. Adequate knowledge of mothers about the critical sings, causes, transmission, prevention, and management of childhood diarrhea should be applied in simple language to communicate the health-related information in clear manner. Also, There is a lack between the understanding the role of ORS and its use. Understanding of ORS is not adequate and it needs reliable efforts to highlight on importance of ORS in resolving dehydration of childhood diarrhea.

\section{COMPETING INTERESTS}

The authors declare that they have no competing interests.

\section{FINANCIAL SUPPORT AND SPONSORSHIP}

Nil.

\section{DATA AVAILABILITY}

Data will be available upon request from the corresponding author of the study

\section{REFERENCES}


1. Bani I, Saeed A, Othman A. Diarrhoea and child feeding practices in Saudi Arabia. Public Health Nutrition.2002; 5(6):727-731.

2. Mukhtar A, Mohamed Izham MI, Pathiyil RS. A survey of mothers' knowledge about childhood diarrhea and its management among a marginalised community of Morang, Nepal. Australas Med J. 2011; 4(9) 474-479.

3. AlAyed MZ, Asaad AM, Mahdi AA, Qureshi MA. Aetiology of acute gastroenteritis in children in Najran region, Saudi Arabia. J Health Spec. 2013; 1:84-89.

4. Centers for Disease Control and Prevention. Diarrhea: common illness, global killer. Available at: https://www.cdc.gov/healthywater/global/diarrhea-burden.html. Accessed. March 15, 2019.

5. Platts-Mills JA, Babji S, Bodhidatta L. Pathogen-specific burdens of community diarrhoea in developing countries: a multisite birth cohort study (MAL-ED). Lancet Glob Health. 2015; 3: e564-e575.

6. Milaat WA, Elassouli SM. Epidemiology of Diarrhea in Two Major Cities in Saudi Arabia. Paediatrica Indonesiana. 1995; 35(5-6):124-31.

7. Tayeb HT, Balkhy HH, Aljuhani SM, Elbanyan E, Alalola S, Alshaalan M. Increased prevalence of rotavirus among children associated gastroenteritis in Riyadh Saudi Arabia. Virology Journal. 2011; $8(1): 548$.

8. Adimora GN, Ikefuna AN, Ilechukwu G. Home management of childhood diarrhoea: need to intensify campaign. Nigerian Journal of Clinical Practice. 2011; 14(2):237-41.

9. Workie HM, Sharifabdilahi AS, Addis EM. Mothers' knowledge, attitude and practice towards the prevention and home-based management of diarrheal disease among under-five children in Diredawa, Eastern Ethiopia, 2016: a cross-sectional study. BMC Pediatrics. 2018; 18(1):358.

10. Al-Ghamdi MA, Bentham G, Hunter PR. Environmental risk factors for diarrhoea among male schoolchildren in Jeddah City, Saudi Arabia. Journal of Water and Health. 2009; 7(3):380-91.

11. Desta BK, Assimamaw NT, Ashenafi TD. Knowledge, Practice, and Associated Factors of HomeBased Management of Diarrhea among Caregivers of Children Attending Under-Five Clinic in Fagita Lekoma District, Awi Zone, Amhara Regional State, Northwest Ethiopia, 2016. Nurs Res Pract. 2017; 2017:8084548.

12. Masiha SA, Khalid A, Malik B, Shah SM. Oral rehydration therapy-knowledge, attitude and practice (KAP) survey of Pakistani mothers. Journal of Rawalpindi Medical College Students Supplement. 2015; 19(1):51-4.

13. Mwambete KD, Joseph R. Knowledge and perception of mothers and caregivers on childhood diarrhoea and its management in Temeke municipality, Tanzania. Tanzania Journal of Health Research. 2010; 12(1):47-54.

14. Raosoft. Sample size calculator. Available at http://www.raosoft.com/samplesize.html. Last accessed on sep 17,2020 .

15. Nigatu M, Tadesse A. Knowledge, perception, and management skills of mothers with under-five children about diarrhoeal disease in indigenous and resettlement communities in Assosa district, western Ethiopia. Journal of Health, Population and Nutrition. 2015; 33(1):20-30.

16. Othero DM, Orago AS, Groenewegen T, Kaseje DO, Otengah PA. Home management of diarrhea among under-fives in a rural community in Kenya: household perceptions and practices. East Afr J Public Health 2008; 5:142-146.

17. MacDonald SE, Moralejo DG, Mathews MK. Maternal understanding of diarrhoea-related dehydration and its influence on ORS use in Indonesia. Asia Pac J Public Health. 2007; 19(1):34-9.

18. Gupta N, Jain SK, Ratnesh, Chawla U, Hossain S, Venkatesh S. An evaluation of diarrheal diseases and acute respiratory infections control programmes in a Delhi slum. Indian J Pediatr. 2007; 74(5):471-6.

19. Delgado MF, Sierra CH, Calvache JA, Rios AM, Mosquera C, Salas I, Agredo F, Meneses R. Maternal knowledge about children's danger signs in acute diarrhoea in an IMCI's frame. Colomb Med. 2006; 37(4):293-8.

20. Walker P. Chapter 16: Diarrhea. In: Krinsky D. Handbook of Nonprescription Drugs: An Interactive Approach to Self-Care. 19th ed. Washington DC, American Pharmacists Association; 2017:268-269.

21. Ashraf A, Bhat MA. Childhood diarrhoea: assessment of knowledge, attitude and practices among 
mothers attending the tertiary care hospital-an observational analytical study. International Journal of Community Medicine And Public Health. 2017; 4(4):1219-22.

22. Khalili M, Mirshahi M, Zarghami A, Rajabnia M, Farahmand F. Maternal knowledge and practice regarding childhood diarrhea and diet in Zahedan, Iran. Health scope. 2013; 2(1):19-24.

23. Masangwi SJ, Grimason AM, Morse TD, Kazembe L, Ferguson N, Jabu GC. Pattern of maternal knowledge and its implications for diarrhoea control in Southern Malawi: multilevel thresholds of change analysis. Int J Environ Res Public Health 2012; 9:955- 69.

24. DenBesten P. Is teething associated with diarrhea?. Western Journal of Medicine. $2000 ; 173(2): 137$.

25. Olson CK, Blum LS, Patel KN, Oria PA, Feikin DR, Laserson KF, Wamae AW, Bartlett AV, Breiman RF, Ram PK. Community case management of childhood diarrhea in a setting with declining use of oral rehydration therapy: findings from cross-sectional studies among primary household caregivers, Kenya, 2007. The American journal of tropical medicine and hygiene. 2011; 85(6):1134-40.

26. WHO . Handbook: IMCI Integrated Management of Childhood Illness. Geneva: WHO; 2005.

27. Kudlova E. Home management of acute diarrhoea in Czech children. J Pediatr Gastroenterol Nutr. $2010 ; 50(5): 510-5$.

28. World Health Orginzation. Country Cooperation Strategy at Glance: Saudi Arabia. Available at: http://apps.who.int/iris/bitstream/10665/136842/1/ccsbrief_sau_en.pdf. Accessed May 14, 2019.

29. Global Media Insight. Saudi Arabia Social Media Statistics 2018. Available at:https://www.globalmediainsight.com/blog/saudi-arabia-social-media-statistics. Accessed May $14,2019$.

30. Ejemot-Nwadiaro RI, Ehiri JE, Arikpo D, Meremikwu MM, Critchley JA. Hand washing promotion for preventing diarrhoea. Cochrane Database of Systematic Reviews. 2015; (9):1-95. 